\title{
Introduction
}

\section{Robert M. Solow}

It is not certain that faster, stabler economic growth is the key to all the other preoccupations of economic policy. But nearly everyone thinks it is; and we can agree that strong economic growth cannot be a disadvantage. Even issues having to do with the inequality of income and wealth, though not automatically solved by economic growth, are thought to be easier to deal with when 'a rising tide is lifting all the boats'.

It is also universally believed, probably rightly, that innovation - both technological and organizational - is the key to faster growth for modern industrial economies. So it is natural that the first two conferences of The Saint-Gobain Centre should have been devoted to the conditions of European growth, and the institutional prerequisites for fast and successful innovation. This volume includes a number of the papers presented at these conferences.

I have already, in these two harmless paragraphs, exemplified what seems to me to be a bad habit. Economists and the broader community interested in these questions tend to speak vaguely of 'faster growth' when they mean, or ought to mean, something different. The theory of economic growth teaches the importance of distinguishing between the long-term sustainable rate of growth (the 'steady-state' growth rate of output or output per person) and the level of the growth path itself. It is much harder and more problematic to achieve a faster long-term growth rate than to raise the level of output all along the long-term growth path. Two economies may have the same long-term rate of growth of output per person, while one of them is consistently 10 per cent more productive than the other, just as two children may be growing in height by the same number of millimetres per year while one of them remains taller than the other.

Suppose the less productive economy can close the productivity gap with the more productive economy. It must temporarily increase its growth rate, but, once it catches up with the other, it may revert to the old common growth rate. That achievement should be described as an improvement in, say, 'growth prospects', but not as an increase in 'the growth rate'.

That is how I propose to interpret the ideas in these essays. Everyone will agree that a better educated, better trained, more skilled workforce will be more productive than it was before. But it is not at all clear that the better- 
educated economy will grow faster. To achieve faster growth might require a faster rate of improvement of the educational level, and that can probably not go on for very long. This is not a cause for frustration; it may be the way nature works. More pointedly, an improvement in the efficiency of the financial system may allow an economy to achieve higher output forever, by permitting a better allocation of capital to available investment opportunities. But the rate of growth will probably increase only temporarily, while the economy adjusts to its new advantage, but not permanently.

The most difficult and interesting case is that an economy may devote more resources, say a larger fraction of GDP, to research and development. It seems likely that more resources will generate more new technology. But will it lead to a permanently faster rate of improvement of technology? We do not know, nor do I think there is any special presumption that it will. That does not mean that an increase in R\&D spending has somehow become insignificant. A proportional increase in the level of national output, maintained forever, is a major achievement: hundreds of billions of euros per year, every year. (It is not impossible that some feasible institutional developments or policy changes will indeed lead to a higher steady-state growth rate. But it is not a claim that should be made casually. The evident convergence among advanced industrial economies is reason for caution.)

The different chapters in this volume direct attention to institutional changes that may well improve what I called the growth prospects of modern economies. They are at least routes to improved economic efficiency. Wolfgang Streeck considers possible changes in corporate organization and governance, an important question that was once rather neglected, but has now come into unhappy prominence. He is not always optimistic about the effects of likely changes. (By the way, one of Enron's many problems was that it was trying to grow too fast, or at least to give the appearance of very rapid growth.) The chapters by David Marsden and Günther Schmid turn to the labour market, an institution that has not lacked for attention in Europe recently. Changes in technology and the composition of demand have altered the nature of the employment relation and the characteristics of a career. Pretty clearly labour-market institutions have to adapt to safeguard both the ability of economies to benefit from innovation and the lifetime welfare of wage and salary workers. It is not certain whether failure to adapt will result in lower efficiency or slower growth, but neither one is desirable.

The remaining chapters, by AnnaLee Saxenian, Timothy Bresnahan, Philippe Aghion, Paul David and Bruno Amable take up different aspects of the system that produces innovations and then translates them into increased productivity. Aghion studies the extremely important question of the relation between the degree of competition in product markets and the incentive for firms to innovate. The question was asked by Joseph Schumpeter long ago, but 
not analytically answered. At one extreme, a complete monopoly can weaken the incentive to innovate: John Hicks suggested that 'The best of all monopoly profits is a quiet life.' At the other extreme it is possible, but not certain, that competition can be too intense: Schumpeter thought that some prospect of monopoly profit would be necessary to induce entrepreneurs to invest valuable resources in research and development. Patent rights are one way to deal with this problem, but the whole character of competition policy may be of even broader importance with respect both to innovation and to general productive efficiency. This is obviously an immediately relevant issue for Europe.

Bresnahan considers another economy-wide question. The surge of productivity growth in the USA between 1995 and 2000 has raised difficult analytical questions about the role of information technology in that episode. (Episode? We do not yet know if that acceleration will last; the recession and stagnation in 2001 and 2002 have muddied the waters, though superficially at least productivity has done better than it usually does in such periods.) We know that the sectors that produce computers and related products contributed a lot to the productivity surge. The extent to which computer use has contributed is less clear, and expert opinions differ. Bresnahan tries to understand the mechanisms that must underlie the productivity effects of information technology.

The chapters by Saxenian, David and Amable reflect on a different and very difficult matter: the internal working of the institutions that create technological and organizational innovations. Saxenian talks of 'technical communities', David of 'research networks' and 'epistemic communities', and Amable of 'social systems of innovation and production'. These locutions suggest that, while it will be necessary to consider incentives, resources and constraints in the usual way, the situation may be more complex. Out of such considerations may eventually come insights into the question mentioned earlier: what is required to convert an increased level of productivity into a faster rate of growth of productivity? And what can we do about it?

This book ends with an overview by Jean-Philippe Touffut of the role of institutions in growth and innovation, outlining in the process the growth possibilities for Europe. 